\title{
Growth of plastic shear zone and its duration inferred from theoretical consideration and observation of an ancient shear zone in the granitic crust
}

\author{
Hidemi Tanaka ${ }^{1}$, Bunichiro Shibazaki ${ }^{2}$, Norio Shigematsu ${ }^{3}$, Koichiro Fujimoto $^{3}$, Tomoyuki Ohtani ${ }^{3}$, \\ Yukari Miyashita ${ }^{3}$, Tomoaki Tomita ${ }^{4}$, Kentaro Omura ${ }^{5}$, Yoji Kobayashi ${ }^{4}$, and Jun Kameda ${ }^{1}$ \\ ${ }^{1}$ Department of Earth and Planetary Science, Graduate School of Science, University of Tokyo, Tokyo 113-0033, Japan \\ ${ }^{2}$ International Institute of Seismology and Earthquake Engineering, Building Research Institute, Tatehara 1, Tsukuba, Ibaraki 305-0082, Japan \\ ${ }^{3}$ Geological Survey of Japan, AIST, Tsukuba, Ibaraki 305-8567, Japan \\ ${ }^{4}$ Institute of Geoscience, University of Tsukuba, Tsukuba, Ibaraki 305-8571, Japan \\ ${ }^{5}$ National Research Institute for Earth Science and Disaster Prevention, Tsukuba, Ibaraki 305-0006, Japan
}

(Received April 5, 2002; Revised August 24, 2002; Accepted October 6, 2002)

\begin{abstract}
A new model for growth of plastic shear zone is proposed based on the basis of a theory of fluid dynamics coupled with a rheological constitutive function, and is applied to a natural shear zone. Mylonite, ultramylonite and other ductile fault rocks are well known to deform in a plastic flow regime. The rheological behavior of these kinds of rocks has been well documented as a non-linear viscous body, which is empirically described as $\dot{\gamma}=A \tau^{n} \exp (-Q / R T)$, where $\dot{\gamma}$ : strain rate, $\tau$ : shear stress, $Q$ : activation energy, $R$ : universal gas constant, $T$ : absolute temperature, and $A$ and $n$ are constants. Strain rate- and temperature-dependent viscosity is obtained by differentiating the equation, and simplified by substituting $n=1$. Then, substitution of the equation into a diffusion equation, $\delta=4 \sqrt{v t}$, derives an equation $\delta=4[t / \rho \cdot A \exp (-Q / R T)]^{1 / 2}$, where $\delta$ : thickness of active layer of viscous deformation, $v$ : kinematic viscosity, and $\rho$ : density. The duration of creep deformation along the ancient plastic shear zone (thickness: $0.076 \mathrm{~m}$ ) is estimated to be around $760 \mathrm{~s}$, in a temperature range from 300 to $500^{\circ} \mathrm{C}$. This estimation is rather good agreement with intermittent creep during inter-seismic period, than steady state creep or co-seismic slip.
\end{abstract}

\section{Introduction}

Deformation in the deeper part of the continental crust frequently involves the formation of localized zones of plastic strain, and these shear zones commonly associate with past records of unstable slip (Hobbs et al., 1986; Harris and Cobbold, 1984; Beach, 1985; Mitra, 1978; Poirier, 1980; Shigematsu and Tanaka, 2000). However, the results from High-T/P experimental studies suggest that the plastic deformation prefers stable slip, which is rather insensitive to the strain (Carter et al., 1981; Shelton, 1981; Christie et al., 1979; Heard, 1972). The conditions favoring or otherwise the formation of such deformation zones in rocks are therefore of great interest of structural geologists and geophysicists.

The stable motion of shear zone in the plastic regime can also be approved by simple theory of fluid dynamics. Thus, as a first step to consider the problem, we will present a new model for growth of plastic shear zone, assuming the constant viscosity of the rocks under the conditions of simple shear. We also applied this model to natural ductile shear zone (Hatagawa shear zone) to estimate the order of duration time of creep deformation.

Copy right(c) The Society of Geomagnetism and Earth, Planetary and Space Sciences (SGEPSS); The Seismological Society of Japan; The Volcanological Society of Japan; The Geodetic Society of Japan; The Japanese Society for Planetary Sciences.

\section{Field Occurrence of Plastic Shear Zone}

In this section, we describe an example of field occurrence of natural plastic shear zone. The swarm of minor shear zones constitute a particular zone of about $500 \mathrm{~m}$ in width at the western region of Hatagawa main shear zone, extending further north and south with a direction of NNE-SSW, subparallel to the Hatagawa main shear zone (Fujimoto et al., 2002). The outcrop of minor plastic shear zone, as shown in the Fig. 1, is well exposed along Takasegawa (outline geology and location of the outcrop are shown in figure 1 in Fujimoto et al., 2002). The plastic shear zone is recognized by existence of asymmetric curviplanar fabric referred to as 'S' surfaces (Fig. 1, Simpson and Schmid, 1983), which indicates a dextral shear sense. The thickness of the shear zone, donated as ' $\delta$ ', is $0.076 \mathrm{~m}$. Shear deformation is more concentrated closer to the boundary surface (A in Fig. 1) along which the thin, very fine-grained layer (B in Fig. 1, ultramylonite layer) is observed. The plastic shear zone is juxtaposed by nondeformed granitic rocks (lower half of Fig. 1), bounded by the surface A.

\section{Boundary Layer Equation and Creep Rheology of Rocks}

A plastic shear zone described in previous section can be modeled as shown in Fig. 2(a), in which viscous half space overlies on the horizontal rigid floor of infinite length and the floor moves to the $x$ direction at $t=0$ with a constant veloc- 


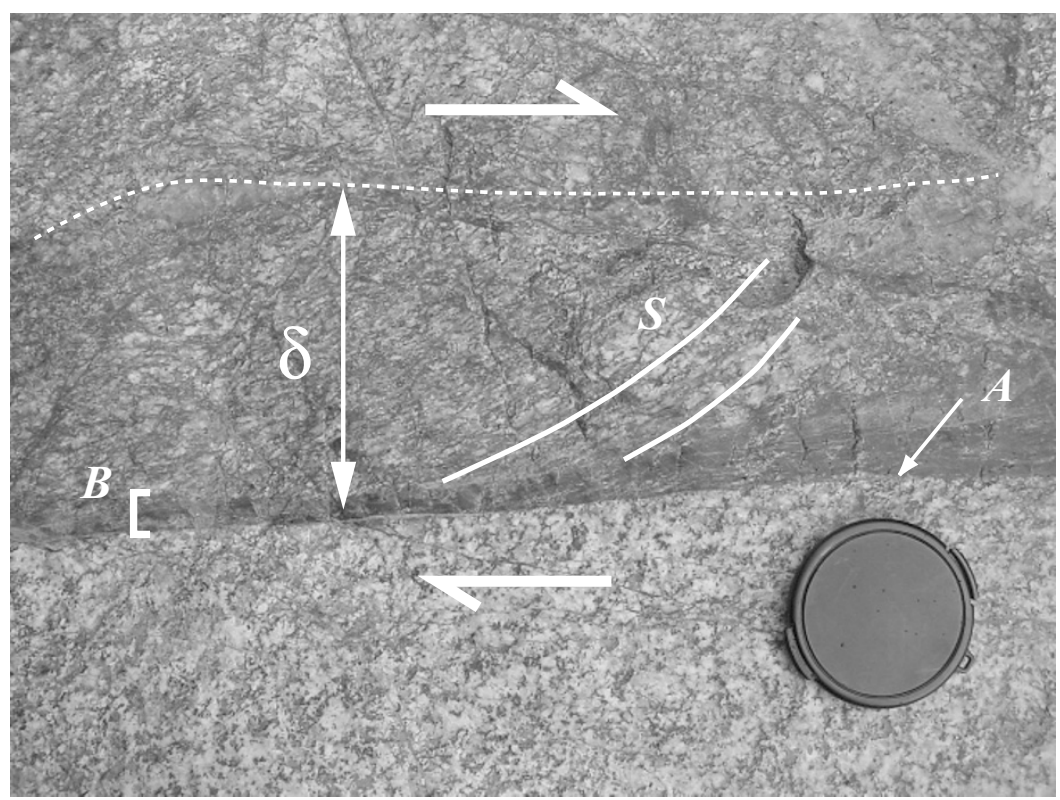

Fig. 1. Photograph showing a right-lateral shear zone with $0.076 \mathrm{~m}(\delta)$ in thickness, at Takasegawa, northwestern part of Hatagawa main shear zone. See the text for implications of abbreviations $\mathrm{A}, \mathrm{B}$, and $\mathrm{S}$.
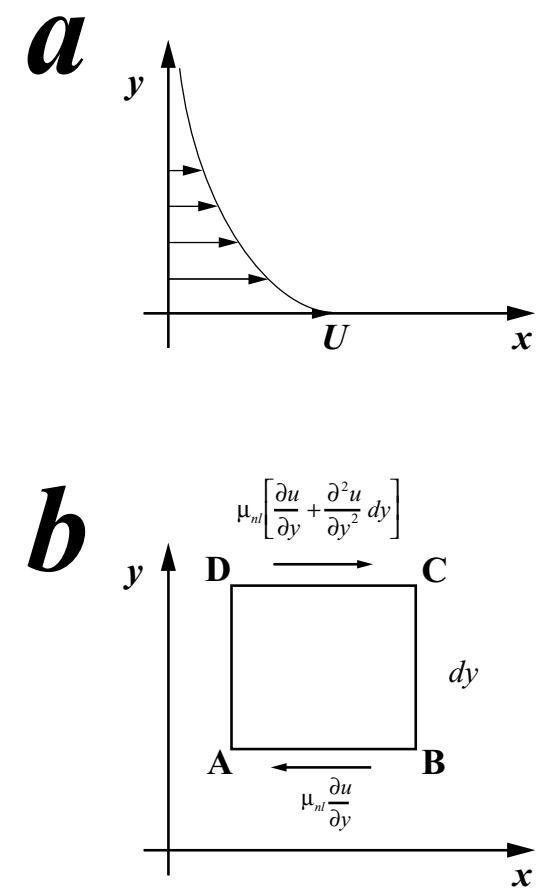

Fig. 2. (a) A model of viscous moment transfer induced by horizontal motion with a constant velocity $U$ of a rigid floor. (b) Moment balance during shear flow for an infinitesimal rectangle ABCD. See the text for explanations.

ity $U$. The horizontal axis $x$ coincides with the boundary between the floor and the viscous body. The edge effect can be neglected in the supposed region since the floor has infinite horizontal length. The viscous half space and rigid floor correspond to deformed and non-deformed domains in Fig. 1, respectively. In order to understand the mechanical behavior of this model, we first introduce boundary layer equations solved by Prandtl (1904). As initial conditions, we assume velocity and pressure gradients along the $x$-axis are 0 .

$$
\frac{\partial u}{\partial x}=0, \quad \frac{\partial p}{\partial x}=0 .
$$

Substitution of Eq. (1) into continuum equation $\partial u / \partial x+$ $\partial v / \partial y=0$ provides:

$$
\frac{\partial v}{\partial y}=0
$$

where $v$ is flow velocity along the $y$-axis. Since the infinitely long rigid floor has no velocity to $y$ direction, $v=0$ on $y=0$, then Eq. (2) gives:

$$
v(y)=0
$$

in the entire region of flow deformation. The conservation of linear momentum based on Eqs. (1) to (3) (Fig. 2(b)) gives:

$$
\rho \frac{\partial u}{\partial t}=\frac{\partial}{\partial y}\left(\mu_{n l} \frac{\partial u}{\partial y}\right)
$$

where $\rho$ is density and $\mu_{n l}$ is non-linear viscosity. For simplicity, we tentatively regard $\mu$ as a constant. Then, Eq. (4) becomes:

$$
\rho \frac{\partial u}{\partial t}=\mu_{l} \frac{\partial^{2} u}{\partial y^{2}}
$$

where $\mu_{l}$ is linear viscosity. Substituting kinematic viscosity $v=\mu_{l} / \rho$ into Eq. (5), we obtain:

$$
\frac{\partial u}{\partial t}=v \frac{\partial^{2} u}{\partial y^{2}} .
$$

This equation can be solved with the following initial and boundary conditions:

$$
\begin{aligned}
& u=0 \rightarrow t \leq 0, y \geq 0 \\
& u=U \rightarrow t>0, y=0 \\
& u=0 \rightarrow t>0, y \gg 1
\end{aligned}
$$


Here, the non-dimensional coordinate and velocity are introduced to avoid complication. The dimensions of $v t$ and $y^{2}$ are the square of the length. Then, the thickness of active deformation layer $(\delta)$ induced by horizontal motion of the rigid floor is proportional to $\sqrt{v t}$. This indicates that $y / \sqrt{v t}$ is an appropriate non-dimensional coordinate. For convenience we introduce:

$$
\eta=\frac{y}{2 \sqrt{v t}}
$$

as a non-dimensional coordinate. As the velocity between 0 and $\delta$ is a function of $\eta$, the time can be eliminated from Eq. (7):

$$
g(\eta)=\frac{u(y, t)}{U} .
$$

Substituting Eqs. (7) and (8) into Eq. (6) and taking $\partial \eta / \partial y=$ $1 / \sqrt{4 v t}$ into account, we obtain:

$$
\frac{d^{2} g}{d \eta^{2}}+2 \eta \frac{d g}{d \eta}=0
$$

which can be integrated as:

$$
\frac{d g}{d \eta}=C \exp \left(-\eta^{2}\right)
$$

where $C$ is a constant. We rewrite the boundary conditions here as:

$$
\begin{aligned}
& \eta=0 \rightarrow g=1 \\
& \eta \gg 1 \rightarrow g=0 .
\end{aligned}
$$

Then Eq. (10) can be integrated as:

$$
g(\eta)=\frac{u}{U}=1-\frac{2}{\sqrt{\pi}} \int_{0}^{\eta} e^{-\eta^{2}} d \eta
$$

where the boundary conditions for $g=0$ is satisfied by using an integral formula:

$$
\int_{0}^{\infty} e^{-\eta^{2}} d y=\frac{\sqrt{\pi}}{2} .
$$

The results shown in Fig. 3 indicates that velocity is approximately 0 at $\eta=2$, where $u / U$ is adopted as the horizontal axis and $\eta$ as the vertical axis. Therefore, from Eq. (7), the thickness of active layer of viscous deformation, $\delta$, can be estimated as:

$$
\delta=4 \sqrt{v t}
$$

This equation has a similar form with that for heat transfer, and indicates that $\delta$ thickens with proportional to the square root of time. We can estimate the duration of creep deformation by applying this equation to natural shear zones if the strain rate is extremely small and so the heat generation by viscous shearing is insignificant.

However, the creep deformation of the crustal rocks in plastic regime shows the non-linear relationship between shear stress and strain rates, which is generally described as:

$$
\dot{\gamma}=A \tau^{n} \exp (-Q / R T)
$$

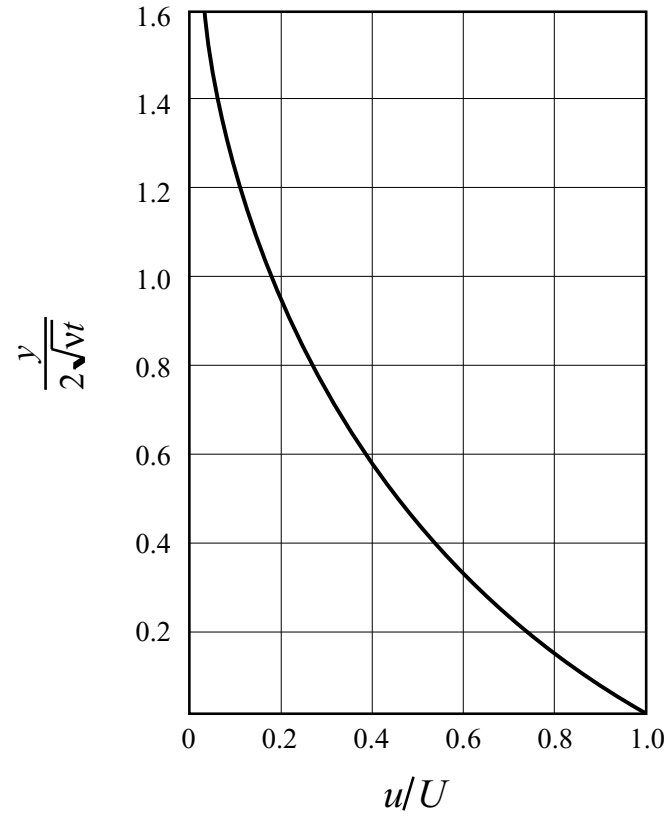

Fig. 3. Normalized velocity gradient across the shear zone. See the text for detailed explanations.

where $\dot{\gamma}$ is strain rate, $\tau$ is shear stress, $Q$ is activation energy, $R$ is universal gas constant, and $T$ is absolute temperature. The effective viscosity can be defined as $\mu_{n l}=d \tau / d \dot{\gamma}$. Then the strain rate dependent viscosity can be estimated by differentiating $\tau$ in Eq. (13) with respect to $\dot{\gamma}$ as:

$$
\mu_{n l}=\frac{d \tau}{d \dot{\gamma}}=\frac{1}{n}\left[\frac{\dot{\gamma}^{1-n}}{A \exp (-Q / R T)}\right]^{1 / n} .
$$

However, because we obtained Eq. (12) on the constant viscosity condition, Eq. (14) is available only for the case $n=1$. Thus,

$$
\mu_{l}=\frac{1}{A \exp (-Q / R T)} .
$$

Substituting Eq. (15) into (12) and assuming constant velocity of deformation, we obtain:

$$
\delta=4\left[\frac{t}{\rho \cdot A \exp (-Q / R T)}\right]^{1 / 2} .
$$

In the next section, we apply this relationship to estimate the duration of creep along natural ductile shear zones.

\section{Estimation of the Duration of Creep along a Plastic Deformation Zone}

Natural shear zones deformed in plastic regime occasionally show a symmetric future, that is, the shear concentration is the highest along the centralized layer and gradually decreasing towards the both marginal parts of the shear zone. Several workers have considered these kinds of shear zones as deformed in a framework of continuum geometry (Ramsay and Graham, 1970; Ramsay and Hubert, 1977). In this study, we would take into account the principles of fluid dynamics for constructing the deformation framework since 


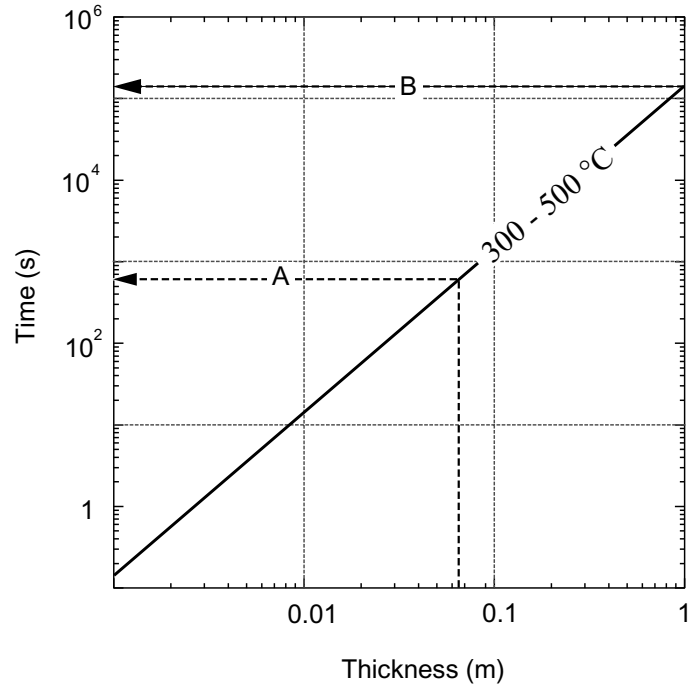

Fig. 4. Relation of the duration of creep with respect to the thickness of plastic shear zone, calculated from Eq. (16). Note that the effect of temperature is negligible.

\section{Discussion and Conclusion}

We proposed a new model describing the growth of plastic shear zone during prolonged shear, and estimated the duration time of creep for a minor shear zone in the Hatagawa shear zone. The result suggests that the duration of shear is about $760 \mathrm{~s}$. The estimation of creep duration is in rather good agreement with the intermittent creep during interseismic periods, than steady state creep, or co-seismic slip. It is also interesting to note that there is little effect of temperature on the duration time is observed at the calculated range $\left(300-500^{\circ} \mathrm{C}\right)$.

It is difficult to evaluate our results at present, because few data/estimation by the other methods are available for comparison and our calculation clearly includes some assumptions and parameters cited from previous research may not be suitable to the natural shear zone. However, beyond these uncertainties, we suggest the dynamic framework presented in this research will give a powerful tool for parameter studies in future field-geological and experimental examinations, which are necessary for reliable estimation of creep in the middle/lower crust and its relation to deformation micromechanisms.

Acknowledgments. The authors thank to Prof. Matu'ura, Tokyo University for critical reviewing of this manuscript.

\section{References}

Beach, A., Retrogressive metamorphic processes in shear zones with specia reference to the Lewisian complex, Jour. Str. Geol., 8, 257-263, 1985.

Carter, N. C., D. A. Anderson, F. D. Hansen, and R. L. Kranz, Creep and creep rupture of granitic rocks, Am. Geophys. Un. Monogr., 24, 61-82, 1981.

Christie, J. M., P. S. Koch, and R. P. George, Flow law of quartzite in the alpha quartz field, EOS, Trans. Am. Geophys. Un., 60, 948, 1979.

Fujimoto, K., T. Ohtani, N. Shigematsu, Y. Miyashita, T. Tomita, H. Tanaka, K. Omura, and Y. Kobayashi, Water-rock interaction observed in the brittle-plastic transition zone, Earth Planets Space, 54, this issue, 1127 1132, 2002.

Harris, L. B. and P. R. Cobbold, Development of conjugate shear bands during bulk simple shearing, Jour. Str. Geol., 7, 37-44, 1984.

Heard, H. C., Steady state flow in polycrystalline halite at pressures of 2 kilobars, Am. Geophys. Un. Monogr., 16, 191-210, 1972.

Hobbs, B. E., A. Ord, and C. Teyssier, Earthquake in the ductile regime?, Pure. Appl. Geophys., 124, 309-336, 1986.

Mitra, G., Ductile deformation zones and mylonites, Am. Jour. Sci., 278, 1057-1084, 1978.

Poirier, J. P., Shear localization and shear instability in materials in the ductile field, Jour. Str. Geol., 2, 135-142, 1980.

Prandtl, L., Über flüssigkeitsbewegung bei sehr kleiner reibung, in Verhandlungen des dritten internationalen Mathematiker-Kongresses, Heidelberg, Germany, 1904 (in German).

Ramsay, J. G. and R. H. Graham, Strain variation in shear belts, Can. Jour Earth Sci., 7, 786-813, 1970.

Ramsay, J. G. and M. I. Hubert, The Techniques of Modern Structural Geology, Vol. 1, Strain Analysis, Academic Press, London, 1977.

Shelton, G., Experimental deformation of single phase and polyphase crystal rocks at high pressure and temperature, Ph.D. Dissertation, Brown University, 1981.

Shigematsu, N. and H. Tanaka, Dislocation creep of fine grained recrystallized plagioclase under low temperature conditions, Jour. Str. Geol., 22, 65-79, 2000.

Simpson, C. and S. M. Schmid, Microstructural indicators of sense of shear in shear zones, Geol. Soc. Am. Bull., 94, 1281-1288, 1983.

H. Tanaka (e-mail: tanaka@eps.s.u-tokyo.ac.jp), B. Shibazaki, N Shigematsu, K. Fujimoto, T. Ohtani, Y. Miyashita, T. Tomita, K. Omura, Y. Kobayashi, and J. Kameda the temperature A 1-meter thick shear zone could be formed by creep with the duration of about 36 hours (B in Fig. 4). 